\title{
Detection of human papillomavirus DNA in semen from patients with intrameatal penile warts
}

\author{
JONATHAN GREEN, * ERIC MONTEIRO, $\dagger$ PATRICIA GIBSON* \\ From the *Virus Reference Laboratory, Central Public Health Laboratory, London and the $\dagger$ Blundell Street \\ Clinic, Department of G U Medicine, Leeds General Infirmary, Leeds LS1 3EX, UK
}

SUMMARY Fifteen semen specimens from 10 men with intrameatal penile warts attending a genitourinary clinic were tested by Southern blot hybridisation for the presence of human papillomavirus (HPV) DNA. Five specimens were positive for HPV types 6/11. This observation may have implications for screening of semen used for artificial insemination by donor.

Human papillomavirus (HPV) infections of the genital tract are sexually transmitted ${ }^{1}$ and an association with benign, premalignant and malignant lesions in both sexes has been suggested. ${ }^{2} \mathrm{HPV}$ is an epitheliotropic virus and genital transmission is thought to be by direct contact between infected and uninfected epithelial surfaces. Involvement of the male urethra by HPV is common and may be the sole manifestation of infection. ${ }^{3}$ Oriel showed that $23 \%$ of 191 men who presented at a sexually transmitted clinic with genital warts had involvement of the urethral meatus ${ }^{4}$ and it has been suggested that the male urethra is a potential reservoir for $\mathrm{HPV}^{5}$ and may be responsible for subclinical transmission. A study at an Artificial Insemination by Donor (AID) centre of men presenting as semen donors showed that some have genital infections such as warts. ${ }^{6}$ There may be serious long term consequences to a recipient resulting from transmission of HPV, particularly of HPV type 16 which is associated with high grade neoplastic lesions of the cervix. ${ }^{7}$ In order to investigate the possibility of HPV transmission we have tested semen specimens from males with penile intrameatal warts for the presence of HPV DNA.

\section{Materials and methods}

Fifteen semen specimens were collected in sterile plastic containers from 10 untreated men with intrameatal penile warts attending a genitourinary clinic.

\footnotetext{
Address for reprints: Jonathan Green, Virus Reference Laboratory, Central Public Health Laboratory, 61 Colindale Avenue, London NW9 5HT, UK.
}

Accepted 18 August 1989
DNA EXTRACTION AND HYBRIDISATION

$0.4 \mathrm{ml}$ of each specimen was digested with proteinase $\mathrm{k}$ $(100 \mu \mathrm{g} / \mathrm{ml})$ in $0.1 \%$ SDS at $37^{\circ} \mathrm{C}$ overnight and the DNA was then extracted twice with an equal volume of phenol/chloroform and once with chloroform/ iso-amyl alcohol (IAA). ${ }^{8}$ RNA was removed from the specimens by digestion with RNAse A $(50 \mu \mathrm{g} / \mathrm{ml})$ at $37^{\circ} \mathrm{C}$ for 15 minutes, and re-extracted once with phenol/chloroform and once with chloroform/IAA. The DNA was precipitated with ethanol, pelleted by centrifugation, dried under vacuum and resuspended in $50 \mu \mathrm{l} \mathrm{TE}$ buffer. The undigested extracted DNA was electrophoresed on a $0.9 \%$ agarose gel and then transferred to a nylon membrane by the method of Southern. ${ }^{9}$

HPV 6, 11, 16 and 18 clones were kindly provided by Dr H zur Hausen (Deutsches Krebsforschungszentrum, Heidelberg). Transformation of bacterial cells with plasmid DNAs and amplification of the plasmids were carried out as described by Maniatis et al. ${ }^{8}$ The clones were extracted and the HPV DNA then separated from vector sequences by restriction enzyme digestion followed by agarose gel electrophoresis and elution.

The viral DNAs were labelled with ${ }^{32} \mathrm{P}$-dCTP by random primer extension to specific activities of $5 \times 10^{8} \mathrm{dpm}$. The probes were used at approximately $10^{6} \mathrm{cpm} / \mathrm{ml}$ hybridisation solution. Hybridisation occurred at $68^{\circ} \mathrm{C}$ overnight. The membrane was then washed under stringent conditions and exposed at $-70^{\circ} \mathrm{C}$ to X-ray film (Amersham MP hyperfilm) for 7 days. The membrane was initially hybridised with a pooled HPV6/11 probe, stripped of probe following exposure to film and reprobed with HPV 16 and then HPV18. The probes were stripped from the membrane by washing with $0.4 \mathrm{M} \mathrm{NaOH}$ for 30 minutes at $45^{\circ} \mathrm{C}$.

Semen specimens positive by Southern hybridisa- 
tion were further examined by restriction enzymic digestion. An $800 \mu \mathrm{l}$ aliquot of each HPV-positive semen specimens was spun in a microcentrifuge for 30 seconds. The DNA was extracted from the pellet and supernatent fractions separately using the procedures described previously. The extracted DNA was then digested simultaneously with BamH1 and EcoR1 restriction enzymes in order to determine the HPV DNA type present. The digests were then electrophoresed on a $0.9 \%$ agarose gel and Southern blotted overnight onto nylon membranes. The membranes were hybridised with specific HPV DNA probes as described previously.

\section{ELECTRON MICROSCOPY}

For examination by electron microscopy, $0.5 \mathrm{ml}$ aliquots of HPV positive semen were centrifuged at $8000 \mathrm{rpm}$ for 1 hour in a Beckman L8-80 centrifuge.

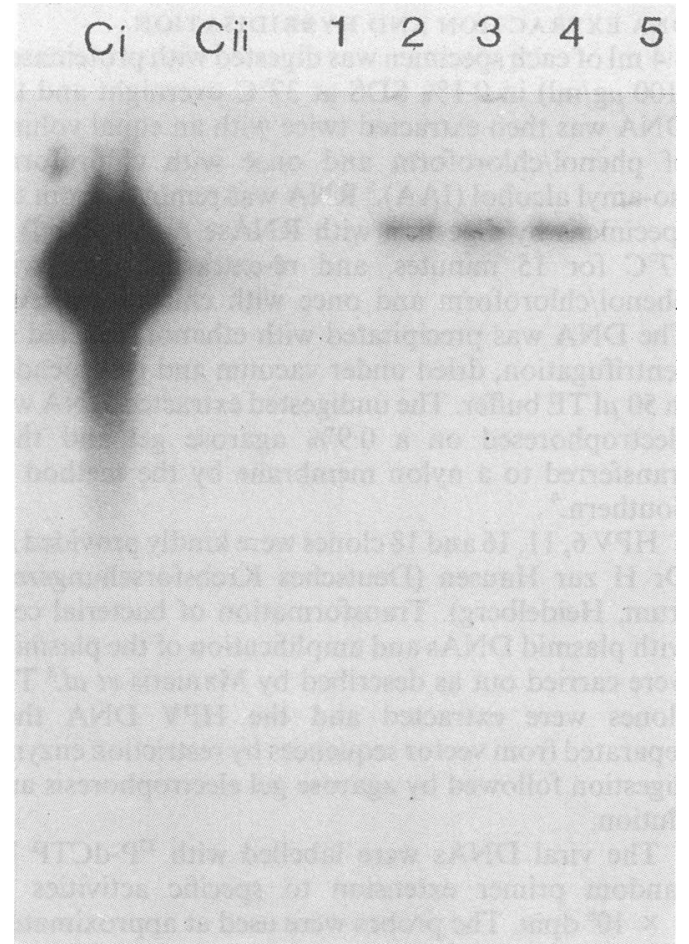

Fig 1 Autoradiograph of semen DNA from five patients with penile intrameatal warts probed with ${ }^{32} P$-labelled HPV6/11 probe. Lane Ci contains linear HPV11 DNA control (100 pg). Lane Cii contains linear HPVI6 DNA control. Lanes 1-5 to show undigested extracted DNA from 5 specimens. Specimens 2, 3 and 4 are positive, but give less intense signals than the 100 pg HPV 11 DNA control. The bands have electrophoresed a shorter distance than the linear control suggesting that this form of the viral DNA is open circular (form II). Specimens 6-15, and HPV 18 control not shown.
The supernatant fraction was then centrifuged for 1 hour at $30000 \mathrm{rpm}$ in a Beckman L8-80 centrifuge. The pellets from the high speed and low speed centrifugation run were resuspended in PBS, stained with $3 \%$ phosphotungstic acid and examined in a Jeol 1200EX electron microscope.

\section{Results}

Five of the 15 specimens tested were found to be positive when hybridised with a pooled HPV 6/11 DNA probe. None were positive by this method for HPV types 16 and 18 . Figure 1 shows the signals obtained from three of the five positive specimens. These were less intense than those from the $100 \mathrm{pg}$ HPV11 control, and the signals from the remaining two positive specimens were even weaker.

Sufficient specimen was available for further investigation of two of the five specimens positive for HPV/11. An aliquot of each was spun in a microfuge for 30 seconds to pellet the spermatozoa and the majority of the cellular material. To differentiate between HPV6 and HPV11, DNA extracted from the supernatants and pellets was digested with Bam HI and Eco RI restriction enzymes (fig 2). For both specimens the HPV DNA was present almost exclusively in the pellet. Specimen four appears to contain only HPV type 11 and specimen three may contain both HPV6 and HPV11. However, further restriction enzyme mapping would be required to show this conclusively.

Two semen specimens which were HPV positive by DNA hybridisation were examined by direct electron microscopy but no virus-like structures were visible in either the pellet or the supernatant fraction.

\section{Discussion}

We have demonstrated the presence of genital types of HPV DNA in semen. Ostrow et al ${ }^{10}$ have previously reported detection of HPV DNA types 2 and 5 in the semen of two patients with the rare autosomal recessive condition epidermodysplasia verruciformis and of a third patient with chronic lymphatic leukaemia. These HPV types are not commonly associated with lesions of the genital tract. These authors did not detect any HPV DNA, using an HPV6 probe under conditions of low stringency, in the semen of 10 healthy donors. Our findings support the suggestion made by this group that semen could be a vehicle for HPV transmission. Using immunochemical staining methods with a group specific antigen to HPV, it has been shown that the majority of cells which express structural antigens and mature virus particles are differentiating keratinocytes in the outer one third of infected stratified squamous epithelium. ${ }^{11}$ We suspect 


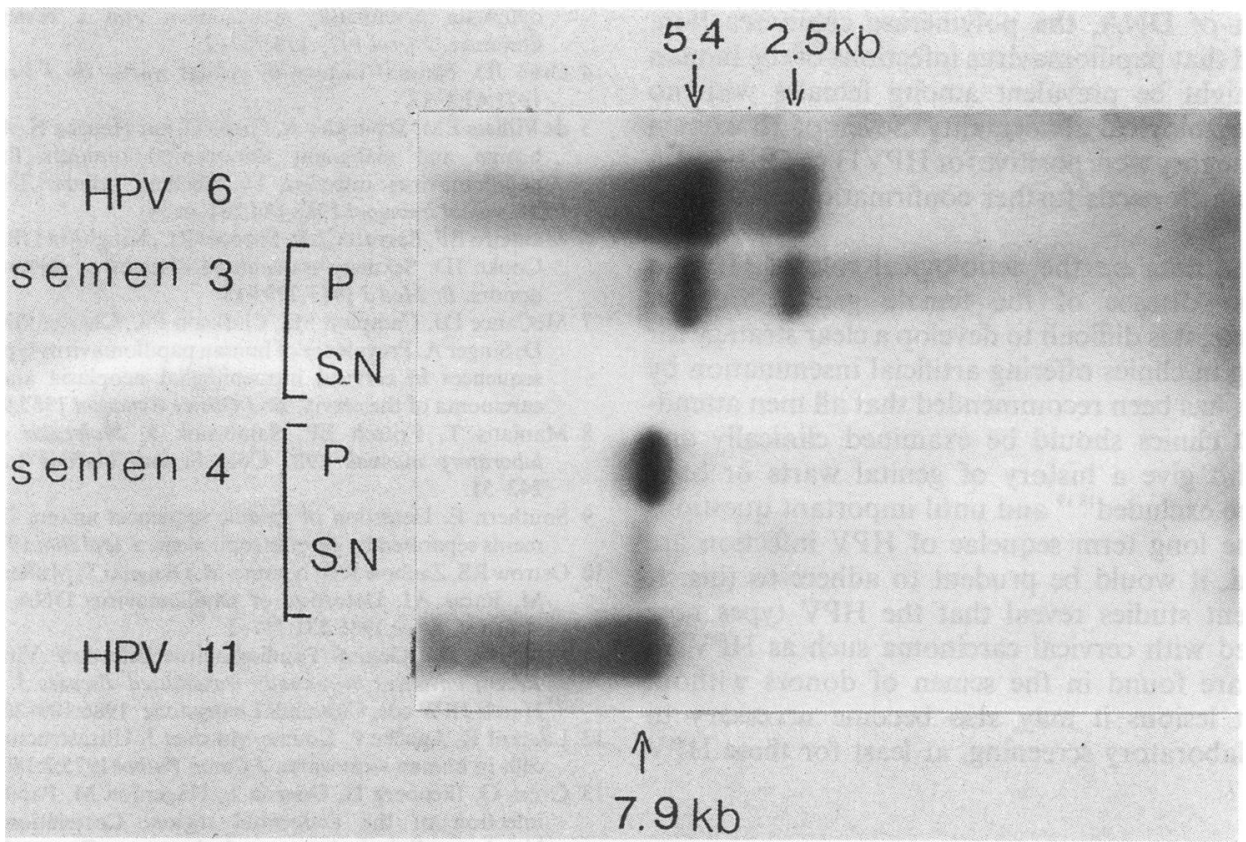

Fig 2 Autoradiograph of Bam HI/Eco RI digested DNA in semen from 2 patients with penile intrameatal warts. Semen pellet and supernatant DNA were extracted separately. HPV DNA was predominantly associated with the pellet (Lanes P) for both specimens 3 and 4 . A linear $7.9 \mathrm{~kb}$ band is visible in both semen 4 lanes suggesting HPVII to be present. Two bands of $5.4 \mathrm{~kb}$ and $2.5 \mathrm{~kb}$ can be seen in the pellet of semen 3 suggesting the presence of HPV6. There is an additional faint band of $7.9 \mathrm{~kb}$ which may indicate the presence of HPV11 also or may be due to incomplete DNA digestion. Insufficient sample was available for confirmation.

that the transmission via semen may occur from urethral lesions from which surface epithelial cells have sloughed during ejaculation.

We have also shown that HPV6 and 11 DNA in the semen specimens was predominantly in the pellet fraction suggesting that the DNA is associated with cellular material rather than present in free virions which would be found in the supernatant. Ostrow's group found HPV associated with the supernatant fraction of the semen. This may reflect differences in virion production of the lesions caused by different HPV types or may be a result of an altered host response in patients with underlying disease. Lesions of the skin associated with HPV types 2 or 5 often contain very large numbers of virions ${ }^{12}$ whereas genital lesions associated with types 6 and 11 usually contain comparatively few. Thus it appears that the "genital" HPV types are more cell-associated and rely less on production of a large number of free virions for transmission. However, only two specimens were examined in this way and confirmation with other specimens would be advantageous.

It is interesting that we only isolated HPV6 and/or 11 in these men, the types associated with benign or mildly dysplastic lesions. This may be due to the small number of patients examined but may be due to patient selection. These types are most commonly related to condylomatous disease whereas type 16 frequently exists in clinically inapparent lesions. ${ }^{1314}$

The presence of the viral genome in semen suggests that semen may act as a vehicle for HPV transmission. It is, however, difficult to determine whether the viral DNA detected is infectious as no established culture system is available. A solution may lie in the future modification of an in vitro culture system using human foreskin keratinocytes to produce normal stratified epithelium. When such a culture was transfected with HPV16 DNA, a histological change similar to cervical intraepithelial neoplasia resulted. ${ }^{\text {is }}$

We are now determining whether HPV can be demonstrated in the semen of males with and without genital warts and this may indicate the extent of "silent" carriage of HPV in the male population. There is an established role for papillomaviruses in some animal and human tumours but at present no clear epidemiological evidence that HPV is the cause of carcinoma of the cervix. ${ }^{16}$ Indeed a recent report on a small study which used a more sensitive method of 
detection of DNA, the polymerase chain reaction, indicated that papillomavirus infections of the human cervix might be prevalent among females with no cervical cytological abnormality. Seven of 10 women in this category were positive for HPV11 or HPV16, ${ }^{17} \mathrm{a}$ finding which needs further confirmation in a larger survey.

Because data on the aetiological role of HPV in malignant disease of the female genital tract is incomplete, it is difficult to develop a clear strategy for screening in clinics offering artificial insemination by donor. It has been recommended that all men attending AID clinics should be examined clinically and those who give a history of genital warts or have lesions be excluded ${ }^{1819}$ and until important questions about the long term sequelae of HPV infection are answered, it would be prudent to adhere to this. If subsequent studies reveal that the HPV types now associated with cervical carcinoma such as HPV 16 and 18 are found in the semen of donors without apparent lesions it may also become necessary to include laboratory screening, at least for these HPV types.

Electron microscopy was performed by Mr Tony Porter, Virus Reference Laboratory, CPHL and we thank him for his help.

\section{References}

1 Levine RU, Crum CP, Herman E, Silvers D, Ferenczy A, Richart RM. Cervical papillomavirus infection and intraepithelial neoplasia: a study of male sexual partners. Obstet Gynecol 1984;64:16-20.

2 Gross G. Lesions of the male and female external genitalia associated with human papillomaviruses. In: Syrjanen K, Gissman L, Koss LG (eds) Papillomaviruses and human disease. Heidelberg: Springer-Verlag 1987.

3 de Benedictus TJ, Marmar JL, Praiss DE. Intraurethral con- dylomata acuminata: management and a review of the literature. J Urol 1977;118:767-9.

4 Oriel JD. Natural history of genital warts. Br J Venereol Dis 1971;47:1-13.

5 de Villiers EM, Schneider A, Gross G, zur Hausen H. Analysis of benign and malignant urinogenital tumours for human papillomavirus infection by labelling cellular DNA. Med Microbiol Immunol 1986;174:281-4.

6 Monteiro EF, Barratt CLR, Spencer RC, Kinghorn GR, Cooke S, Cooke ID. Sexually transmitted diseases in potential semen donors. Br Med J 1987;295:418.

7 McCance DJ, Campion MJ, Clarkson PK, Chester OM, Jenkins D, Singer A. Prevalence of human papillomavirus type 16 DNA sequences in cervical intraepithelial neoplasia and invasive carcinoma of the cervix. Br J Obstet Gynaecol 1985;92:1101.

8 Maniatis T, Fritsch EF, Sambrook J. Molecular cloning: $a$ laboratory manual. 1982 Cold Stream Harbor Laboratory. 242-51.

9 Southern E. Detection of specific sequences among DNA fragments separated by gel electrophoresis. J Mol Biol 1975;98:503.

10 Ostrow RS, Zachow KR, Nimura M, Okagaki T, Muller S, Bender M, Faras AJ. Detection of papillomavirus DNA in human semen. Science 1986;231:731-3.

11 McCance DJ. Genital Papillomavirus Infection: Virology. In: Recent advances in sexually transmitted diseases 3. Oriel JD, Harris JRW eds. Churchill Livingstone. 1986:109-26.

12 Laurent R, Agache P, Coume-Marquet J. Ultrastructure of clear cells in human viral warts. J Cutan Pathol 1975;2:140-48.

13 Gross G, Ikenberg H, Gisman L, Hagerdon M. Papillomavirus infection of the anogenital region: Correlation between histology, clinical picture, and virus type. Proposal of a new nomenclature. J Invest Dermatol 1985;85:147-52.

14 Barrasso R, De Brux J, Croissant O, Orth DVM. High prevalence of papillomavirus-associated penile intraepithelial neoplasia in sexual partners of women with cervical intraepithelial neoplasia. N Engl J Med 1987;317:916-23.

15 McCance DJ, Kopan R, Fuchs EV, Laimins LA. Human Papillomavirus Type 16 alters differentiation of human epithelial cells in vitro. British Society for Colposcopy and Cervical Pathology. Birmingham, England. 1988.

16 Munoz N, Bosch X, Kaldor JM. Does human papillomavirus cause cervical cancer? The state of the epidemiological evidence. Br J Cancer 1988;57:1-5.

17 Young LS, Bevan IS, Johnson MA, et al. The polymerase chain reaction: a new epidemiological tool for investigating cervical human papillomavirus infection. $\mathrm{Br}$ Med J 1989;298:14-8.

18 American Fertility Society. New Guidelines for the use of semen donor insemination. Fertil Steril 1986;46(4), (Suppl 2): 95S-110S.

19 Barratt CLR, Monteiro EF, Mayor II, Cooke S, Cooke ID. Screening Semen Donors for Sexually Transmitted Disease in the UK. A survey. Br J Obstet Gynaecol 1989;96:461-6. 